\title{
POLICY RELEVANT ECOSYSTEM SERVICES VALUATION; RAINFOREST NON-TIMBER PRODUCTS
}

\author{
B M S Batagoda \\ Ministry of Forestry and Environment
}

One recent study has estimated the current economic value of seventeen ecosystem services on a biosphere-wide basis at between US\$ $16-54$ trillion $\left(10^{12}\right)$ per year, representing an average annual value some 1.8 times the current global gross national products (Costanza 't al. 1997). Such global aggregate values, while they serve to raise awareness and stimulate dialogue hetween scientists, social scientists. policymakers and citizens, should not be laken too literally. The challenge will be to quantily in monetary terms and prove low valuable ecosystem services are: as well as to formulate mechanisms by which such function-based values can be realistically appropriated by society. In a much quoted paper (Peters et al.. 1989) the economic value (net present value) of the fruits and latex harvest from an Amazonian forest was estimated to be US\$ 6,330 hat. Even more significantly, it was also clatimed that such an economic return was sawntimber extraction/production $\left(\mathrm{NPV}=\right.$ US\$ $\left.1,000 \mathrm{ha}^{-1}\right)$. timber and pulpwood extraction/production $(\mathrm{NPV}=$ US\$ 3,184 $\mathrm{ha}^{-1}$ ) or fully-stocked cattle pasture (NPV $=$ US $\$ 2,2960 \mathrm{ha}^{-1}$ ). This is a strong conclusion with obvious implications for tropical forest conservation verses development policy. The temptation then is that such findings are generalised.

This paper focuses on tropical rainforest ecosystems and the use value of their non-timber forest products (NTFPs) provisions to test whether this conclusion is universally valid? The study has rigorously applied its data collection and analysis to validity and reliability protocols in order to estimate the policy relevant NTFPs value derived from the Sinharaja rainforest in Sri Lanka. This forest land use has then been compared with alternative land us options in a cost-benefit analysis. The results indicate that the NPV of the actual NTFPs llow from the Sinharaja is USS $147 \mathrm{ha}^{-1}$ which is significantly lower than the land clearance value US\$ $4281 \mathrm{hat}^{-1}$ (teal cultivation). This means that previous studies have significantly overestimated NTFPs value, and consequently that biodiversity conservation policy cannot be economically justified (economic efficiency criterion) on the basis of sustainable NTFPs collection alone. Such a strategy does, however, also have other wider social benelits for local forest village communities such as income distribution effects. Conservation of the forest ecosystem would also generate other uses and non-use values linked to other 'NTFPs-compatible' forest function services. An economic case for such a conservation strategy will have to be based on the multiple services value that a given 'healthy' forest ecosystem cin provide sustainably over time.

Proceedings of the Fourth Anmual Forestry and Environment Sympessium 1998 of the Department of Forestry and Envirommental Science, University of Sri Jayewardenepura. Sri Lanka 